\title{
Droop control method for load share and voltage regulation in high-voltage microgrids
}

\author{
Zhikang SHUAI ${ }^{1}$, Shanglin MO ${ }^{1}$, Jun WANG ${ }^{1}$, Z. John SHEN ${ }^{2}$, \\ Wei TIAN ${ }^{2}$, Yan FENG ${ }^{1}$
}

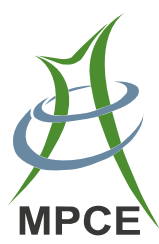

\begin{abstract}
When the line impedance is considered in the microgrid, the accuracy of load sharing will decrease. In this paper, the impact of line impedance on the accuracy of load sharing is analyzed. A robust droop control for a highvoltage microgrid is proposed based on the signal detection on the high-voltage side of the coupling transformer. For a high-voltage microgrid, the equivalent impedance of coupling transformer connecting distributed generator with the grid is usually the dominate factor. Compared with the conventional droop control strategy, the proposed control method in this paper detects the feedback signal from the high-voltage side of the coupling transformer. The impact of line impedance on the load sharing accuracy can be
\end{abstract}

CrossCheck date: 17 November 2015

Received: 11 October 2015 / Accepted: 22 December 2015/Published online: 19 January 2016

(c) The Author(s) 2016. This article is published with open access at Springerlink.com

$\triangle$ Shanglin MO

mos10424@qq.com

Zhikang SHUAI

shuaizhikang-001@163.com

Jun WANG

jwangncsuchn@gmail.com

Z. John SHEN

zjohnshen@gmail.com

Wei TIAN

tw@kawk.iit.edu

Yan FENG

Fengyan@qq.com

1 National Power Transformation and Control Engineering Technology Research Center, Hunan University, Changsha 410082, China

2 Electrical and Computer Engineering, Illinois Institute of Technology, Chicago, IL 60616, USA mitigated significantly. The proposed droop control only changes the detection point of the feedback signal, thus it is easy to be implemented. The PSCAD/EMTDC simulation results show the effectiveness of the proposed robust droop control concept in load sharing and voltage regulation with highly accuracy.

Keywords Microgrid, High-voltage, Coupling transformer, Droop control, Accreted load sharing, Voltage regulation

\section{Introduction}

In order to address the environmental pollution and energy crisis, many distributed generations (DGs), e.g., solar energy, wind energy, microturbines, and fuel cells are widely used. These DGs are connected to the utility grid via inverters, which are also known as the microgrid $[1,2]$. The operation mode of the microgrid can be switched between grid-connected and islanded mode flexibly [3]. A necessary problem for parallel-operated DGs in a microgrid is how to avoid the circulating current among them. One of the key techniques is to use droop control $[4,5]$, which has been widely used in conventional synchronous generators [6] and uninterruptible power supply (UPS) [7]. Its advantage is that each DG is able to be operated independently without any critical communication.

Although the droop control is widely used as a wireless control strategy for load sharing, it has some drawbacks that limit its application. For instance, the load sharing accuracy is degraded if the per-unit impedances (the output impedance and the line impedance) of each DG are unbalanced [8]. Usually, P-f and Q-V droop control are used when the equivalent impedance which 
connecting DGs to the gird is inductive in a microgrid [9]. The active power can be shared accurately using P-f droop control since it is just based on the frequency of the microgrid. However, the DG voltage output in Q-V droop control is different with the voltage at the point of common coupling (PCC) because of the different line impedances. Thus the accuracy of reactive power sharing using Q-V droop control is usually substantially affected by the equivalent impedance of DG and line impedance [10].

In order to enhance the accuracy of reactive power sharing, the droop control gains are necessary to be optimized $[11,12]$. However, there are still inherent tradeoff between the load sharing accuracy and voltage regulation. Therefore, these methods are only valid for the microgrid with short distribution lines where the line impedance is negligible. Recently, the virtual reactor or integral unit to adjust the equivalent impedance of DGs is added to the conventional droop control loop [13, 14]. However, the line impedance is still unknown even the equivalent impedance of DGs can be established. Thus, the line impedances are detected or calculated in some literatures $[15,16]$ in order to mitigate their influence. However, it is quite complicated to implement. In some cases, the external communication is still adopted [17]. However, the reliability and stability of microgrids will be affected substantially by the communication system. The complicated communication system would also increase the difficulties significantly in design and implementation of large scale microgrids.

Reference [8] proposed a robust droop control and the robustness of the voltage output and load sharing accuracy could be enhanced obviously. However, it is only suitable for the centralized microgrid with communication equipment. Besides, a virtual impedance unit added in control loop should be bigger enough so that the effect of line impedance can be omitted, which is complex and limited to its application. Nowadays, the high-voltage large scale microgrid for campus and island are most likely to be developed [18, 19]. In these kinds of microgrids, DGs are always connected to the utility grid by a step-up coupling transformer. As the equivalent impedance of the coupling transformer is usually much larger than that of the line, in this sense, the effect of line impedance may be negligible. If the load sharing error caused by the equivalent impedance of transformer can be eliminated, the performance of microgrids can also be improved obviously.

A robust droop control method is proposed in this paper which is suitable for high-voltage microgrids and easy to implement. In Section 2, the impact of line impedance on load sharing accuracy is analyzed. In Section 3, the improved robust droop control is presented. The system model for analyzing the influence of system parameters on the performance of the proposed control concept and the design consideration of robust droop control gain are presented in Section 4. The PSCAD simulation results are given in Section 5, followed by conclusions in Section 6 .

\section{Impacts of line impedance on load sharing in microgrids}

Figure 1 shows a general scheme of a microgrid which consists of sets of microsource and energy storage, distributed loads and electric power interfaces inverter connected to the step-up coupling transformer. Besides, the microgrid can be connected to the utility grid operating in grid-connection mode if the switch STS is turned on. When the utility grid is not present, the DG units should be able to share the total power demanded together.

Figure 2 shows the equivalent high-voltage side circuit of the microgrid. $E_{i} \angle \theta_{i}(i=1,2, \cdots)$ is the voltage output of $\mathrm{DG}_{i} ; P_{i}$ and $Q_{i}$ are the active and reactive power flowing into loads generated by $\mathrm{DG}_{i}$, respectively; $V \angle \theta$ is the $\mathrm{AC}$ common bus voltage; $Z_{i} \angle \varphi_{i}$ is the equivalent impedance.

The current output of each DG is

$\boldsymbol{I}_{i}=\frac{E_{i} \cos \delta_{i g}-V+\mathrm{j} E_{i} \sin \delta_{i g}}{R_{i}+\mathrm{j} X_{i}}$

where $X_{i}$ and $R_{i}$ are the equivalent inductive and resistive component, respectively; $\delta_{i g}$ is the phase difference between $\boldsymbol{E}_{i}$ and $V, \delta_{i g}=\theta_{i}-\theta$.

The active power and reactive power output of each DG are calculated as

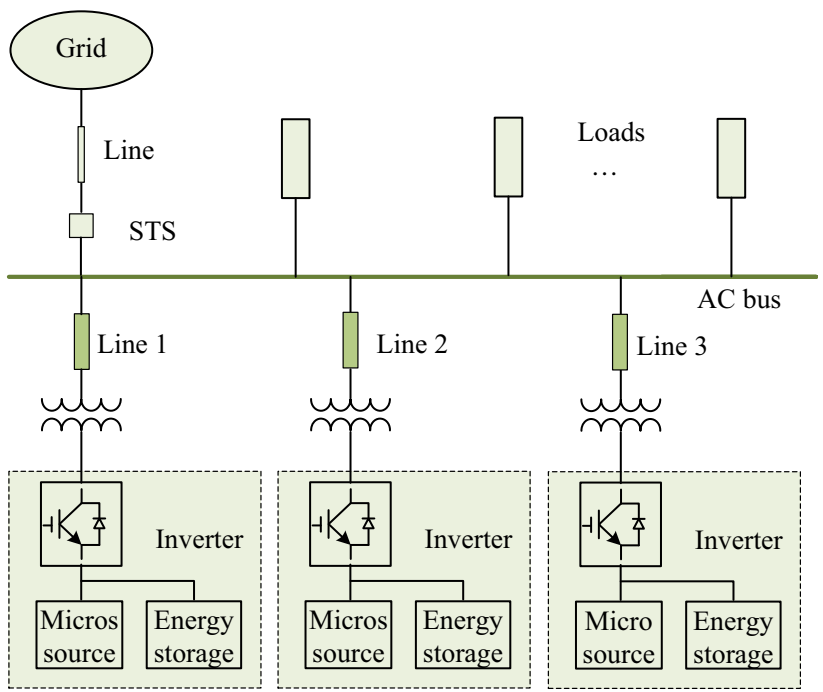

Fig. 1 A high-voltage microgrid 


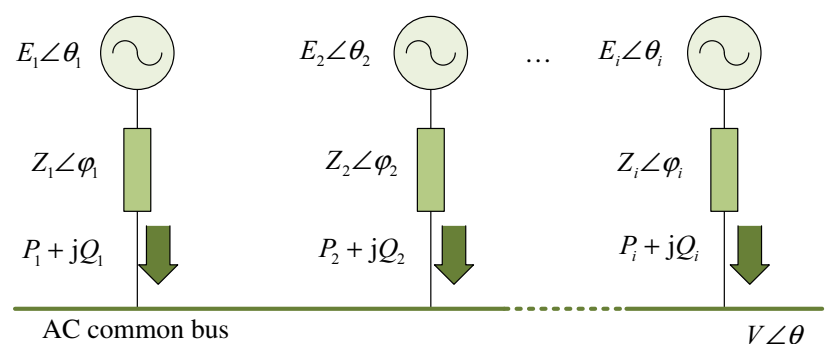

Fig. 2 Equivalent circuit of a high-voltage microgrid connected to a common bus

$$
\begin{aligned}
P_{i} & =\frac{X_{i}}{Z_{i}} \frac{E_{i} V}{Z_{i}} \sin \delta_{i g}+\frac{R_{i}}{Z_{i}} \frac{V\left(E_{i}-V \cos \delta_{i g}\right)}{Z_{i}} \\
Q_{i} & =-\frac{R_{i}}{Z_{i}} \frac{E_{i} V}{Z_{i}} \sin \delta_{i g}+\frac{X_{i}}{Z_{i}} \frac{V\left(E_{i}-V \cos \delta_{i g}\right)}{Z_{i}}
\end{aligned}
$$

In high-voltage power systems, the inductive reactance $X_{i}$ is much larger than resistive component $R_{i}$ which means $\cos \delta_{i g} \approx 0$ and $\sin \delta_{i g} \approx \delta_{i g}$, so (2) can be simplified as

$P_{i}=\frac{E_{i} V}{X_{i}} \delta_{i g}$

$Q_{i}=\frac{V}{X_{i}}\left(E_{i}-V\right)$

Equation (3) is the theoretical basis of traditional P-f and $\mathrm{Q}-\mathrm{V}$ droop control. Accordingly, the frequency and voltage output of DGs can be regulated as

$\omega_{i}=\omega^{*}-n_{i} P_{i}$

$E_{i}=E^{*}-m_{i} Q_{i}$

where $\omega_{i}$ and $\omega^{*}$ and are the frequency output and the rated frequency of $\mathrm{DG}_{i} ; E^{*}$ is the rated voltage of high-voltage microgrid; $n_{i}$ and $m_{i}$ are the frequency droop gain and voltage droop gain, respectively.

With the traditional and normal droop control strategy, when the microgrid operates in steady state, it will share the same frequency with utility grid. Thus, the frequency and active power of $\mathrm{DG}_{i}$ can be described as

$\left\{\begin{array}{l}\omega_{1}=\omega_{2}=\ldots=\omega_{i} \\ n_{1} P_{1}=n_{2} P_{2}=\ldots=n_{i} P_{i}\end{array}\right.$

However, the reactive power $Q_{i}$ mainly depends on $\boldsymbol{E}_{i}, \boldsymbol{V}$ and the line impedance $\boldsymbol{Z}_{i}$ [20]. $\boldsymbol{V}$ can be expressed as

$\mathbf{V}=\left(E_{1} \angle \theta_{1}, \ldots, E_{i} \angle \theta_{i}, R_{1}+\mathrm{j} X_{1}, \ldots, R_{i}+\mathrm{j} X_{i}\right)$

As can be seen from (6), the accurate reactive power sharing is difficult to be implemented with the conventional droop control scheme unless the impedance of distribution lines is strictly the same as (7).
$\left\{\begin{array}{l}E_{1}=E_{2}=\ldots=E_{i} \\ \frac{m_{1}}{X_{1}}=\frac{m_{2}}{X_{2}}=\ldots=\frac{m_{i}}{X_{i}}\end{array}\right.$

Due to the unpredictable and unchangeable of the microgrid parameters, (7) is almost impossible to be satisfied, especially the per-unit impedance. Therefore, how to achieve accurate reactive power sharing is one of the key topics in microgrids.

For the inverter-interfaced high-voltage microgrid, DGs are always connected to the utility grid through a step-up coupling transformer. Thus, a simplified and general topology of a typical high-voltage microgrid system with paralleled DGs is shown in Fig. 3. $L_{\mathrm{s} i}$ and $C_{\mathrm{s} i}$ are inductor and capacitor of the LC filter, respectively. $V_{\mathrm{f} i}$ is the voltage of the inverter output port. $K_{\mathrm{T} i}$ is the voltage ratio of transformer; $V_{\mathrm{T} i}$ and $i_{\mathrm{T} i}$ are the output voltage and current at the high-voltage side of transformer $T_{i}$, respectively; $V_{i}$ and $i_{i}$ are the output voltage and current at the low-voltage side of transformer $T_{i}$, respectively; $X_{\mathrm{Li}}$ is the equivalent impedance of Line $i$. In additional, the fundamental frequency element of $V_{\mathrm{f} i}$ is equal to $E_{i}$. Therefore, the output impedances $X_{i}$ is

$X_{i} \approx \omega k_{\mathrm{T} i}^{2} L_{\mathrm{s} i}+X_{\mathrm{T} i}+X_{\mathrm{L} i}$

where $X_{\mathrm{T} i}$ is the transformer equivalent impedance in the high-voltage side of step-up coupling transformer.

Besides, coupling transformers are usually used for high-voltage microgrids. Hence, compared with a lowvoltage microgrid, the impact of the coupling transformer in the high-voltage microgrid should be considered when deal with the influence of line impedance. Especially for a large-capacity transformer, the inductive component of the short circuit impedance is usually larger than the resistive component. The short-circuit reactance $X_{\mathrm{T}}$ of the transformer is calculated [21].

$X_{\mathrm{T}}=\frac{V_{\mathrm{s}}}{100} \frac{V_{\mathrm{N}}^{2}}{S_{\mathrm{N}}}$

where $S_{\mathrm{N}}$ and $V_{\mathrm{N}}$ are the apparent power and rated voltage of the transformer; $V_{\mathrm{s}}$ is the percentage of short-circuit voltage.

It is noted that the inductive component $X_{\mathrm{T}}$ of the transformer with large capacity in a high-voltage microgrid system is bigger enough so that the line impedance could

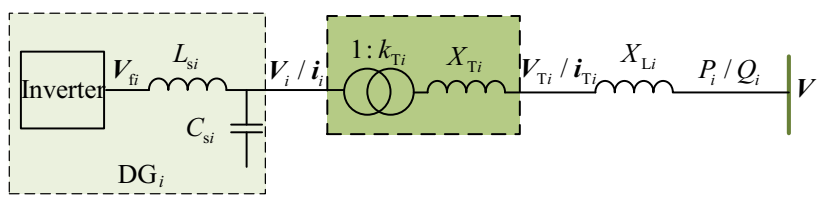

Fig. 3 A simplified and general topology of a typical high-voltage microgrid system 
be omitted. For example, a transformer with the parameters: $S_{\mathrm{N}}=0.1 \sim 1$ MVA, $V_{\mathrm{N}}=10 \mathrm{kV}, V_{\mathrm{s}}=10 \%$, then, $X_{\mathrm{T}}=10 \sim 100 \Omega$. In addition, the line impedance $X_{\mathrm{L}}$ of a high-voltage microgrid is generally about $0.5 \Omega$. Therefore, in most cases, $X_{\mathrm{T}} \gg X_{\mathrm{L}}$ can be established for the highvoltage microgrid. Thus, it is noted that $V_{\mathrm{T} i} \approx V$ in a highvoltage microgrid with the step-up coupling transformer.

Reference [8] proposed a robust droop control based on the detection of AC common bus voltage $\boldsymbol{V}$ and current $i_{\mathrm{T} i}$ flowing into the $\mathrm{AC}$ common bus, which can not only overcome the influence of system unbalanced impedance but also pull up the AC common bus decreased voltage due to the output impedance and voltage droop coefficient. However, this robust droop control is only suitable for microgrids with communication equipments, which limits its application. Fortunately, based on the above analysis, the equivalent impedance of coupling transformer is usually much larger than that of the line. It would be highly advantageous to develop a robust droop control strategy without signals communication which can eliminate the influence of the mismatched equivalent line impedance.

\section{Robust droop control strategy for high-voltage microgrid}

If the robust droop method proposed in reference [8] is applied in the high-voltage microgrid as shown in Fig. 3, in addition to current flowing into $\mathrm{AC}$ common bus, the remote bus voltage $\boldsymbol{V}$ also should be sampled by voltage sensors as shown in Fig. 4 with $K_{\mathrm{s}}$ connected to Channel 1 . Compared with the traditional droop control, there is a great difference that the drop voltage $E^{*}-V$ is fed back via an amplifier $K_{\mathrm{e}}$, and then the feedback signal is added to $m_{i} Q_{i}$ on account of $\mathrm{Q}-\mathrm{V}$ droop effect. As to be explained below, it is able to maintain accurate proportional load sharing and voltage robustness in spite of mismatched line impedances.

When the microgrid with the robust droop control operates in steady state, the condition (10) is satisfied.

$K_{\mathrm{e}}\left(E^{*}-V\right)=m_{i} Q_{i}$

The left-hand side of the above is always the same for all DGs connected to microgrid as long as $K_{\mathrm{e}}$ is set the same. Hence, the right-hand sides of (10) are equal. Then

$m_{1} Q_{1}=m_{2} Q_{2}=\ldots=m_{i} Q_{i}$

Assume that

$m_{1} S_{1}=m_{2} S_{2}=\ldots=m_{i} S_{i}$

where $S_{i}$ is the rated power output of $\mathrm{DG}_{i}$.

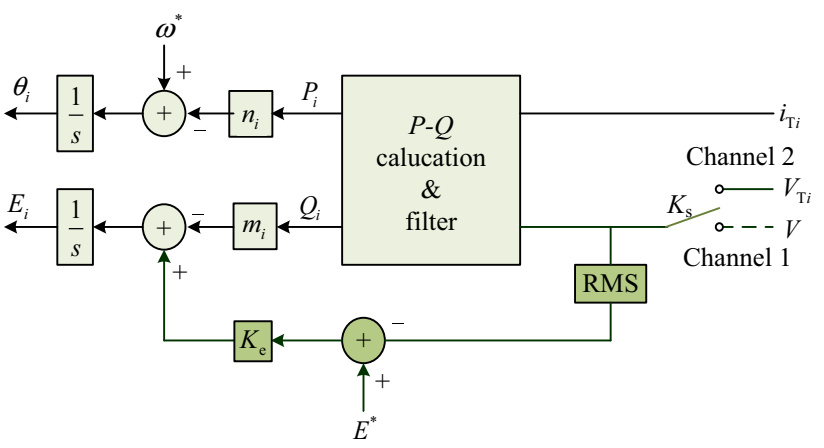

Fig. 4 Robust droop control for high-voltage microgrid

Thus, the supply power of each inverter for loads is proportional to its capacity of inverter, and (13) can be derived.

$\frac{Q_{1}}{S_{1}}=\frac{Q_{2}}{S_{2}}=\ldots=\frac{Q_{i}}{S_{i}}$

Accordingly, regardless of the mismatched line impedance, the reactive power output of DG is proportional to its capacity with the robust droop control, and then the high accuracy of reactive power sharing can be achieved.

As shown in Fig. 4, in order to achieve a highly load sharing accuracy with the robust droop control, the common bus voltage and power of each DG flowing into a concentrated load have to be detected. Thus, this kind of droop control concept is only suitable for the microgrid with concentrated loads. Also, the transmission process of feedback signals for a long-distance may also challenge the load sharing accuracy and reliability of microgrids. According to the analysis in Section 2, the equivalent impedance of coupling transformer is generally much larger than the line impedance for a high-voltage microgrid, namely $X_{\mathrm{T} i} \gg X_{\mathrm{L} i}$, so $V_{\mathrm{T} i}$ is much close to $V$. Thus, it is possible to applied robust power droop control by detecting $V_{\mathrm{T} i}$ at the high-voltage side of step-up coupling transformer without communication devices and instead of AC common bus voltage $V$.

Accordingly, a new robust droop control is proposed based on the detection of $V_{T i}$ and the current output at the high-voltage side of transformer in this paper. The control block of the new robust droop control is shown in Fig. 4 when $K_{\mathrm{s}}$ is connected to Channel 2. So (10) can be rewritten as

$K_{\mathrm{e}}\left(E^{*}-V_{\mathrm{T} i}\right)=m_{i} Q_{i}$

The Q-V droop expression can be expressed as

$V_{\mathrm{T} i}=E^{*}-\frac{m_{i}}{K_{\mathrm{e}}} Q_{i}=E^{*}-\frac{m_{i} Q_{i}}{K_{\mathrm{e}} E^{*}} E^{*}$ 
where $m_{i} Q_{i} /\left(K_{\mathrm{e}} E^{*}\right)$ is the voltage drop ratio. Note that the overall effective voltage drop coefficient $m_{i} / K_{\mathrm{e}}$ in (15) is much smaller than that $m_{i}$ in the conventional droop controller as long as the $K_{\mathrm{e}}$ is big enough. In addition, meanwhile, it means the robust droop controller could achieve fast response despite of a smaller voltage droop coefficient and the robustness of output voltage is improved.

Assume that

$$
\left\{\begin{array}{l}
Q_{\text {desired }}=\frac{S_{i}}{\sum_{i=1}^{n} S_{i}} Q_{\text {load }} \\
Q_{i}=Q_{\text {desired }}+\Delta Q_{i}
\end{array}\right.
$$

where $Q_{\text {load }}$ and $Q_{\text {desired }}$ are the real reactive power load and desired reactive power of $\mathrm{DG}_{i}$, respectively; $\Delta Q_{i}$ is the error of $Q_{i}$ and $Q_{\text {desired }} ; n$ is the sum of inverter. Note that there must be a voltage $V_{\mathrm{T}}$ within the scope of real field which could satisfy (17).

$$
K_{\mathrm{e}}\left(E^{*}-V_{\mathrm{T}}\right)=m_{i} Q_{\text {desried }}
$$

Thus, according to (14), (16) and (17), we can obtain

$$
K_{\mathrm{e}}\left[E^{*}-V_{\mathrm{T}}+\left(V_{\mathrm{T}}-V_{\mathrm{T} i}\right)\right]=m_{i}\left(Q_{\text {desried }}+\Delta Q_{i}\right)
$$

So (18) can be rewritten as

$K_{\mathrm{e}}\left(V_{\mathrm{T}}-V_{\mathrm{T} i}\right)=m_{i} \Delta Q_{i}$

According to the conservation of energy theorem, it is noted that the system must satisfy

$$
\left\{\begin{array}{l}
Q_{\text {desried }} \sum_{i=1}^{n} S_{i}=Q_{\text {load }} S_{i} \\
\sum_{i=1}^{n} \Delta Q_{i}=0 \\
\sum_{i=1}^{n} Q_{i}=Q_{\text {load }}
\end{array}\right.
$$

According to (19) and (20), (21) can be achieved through accumulating and simplifying.

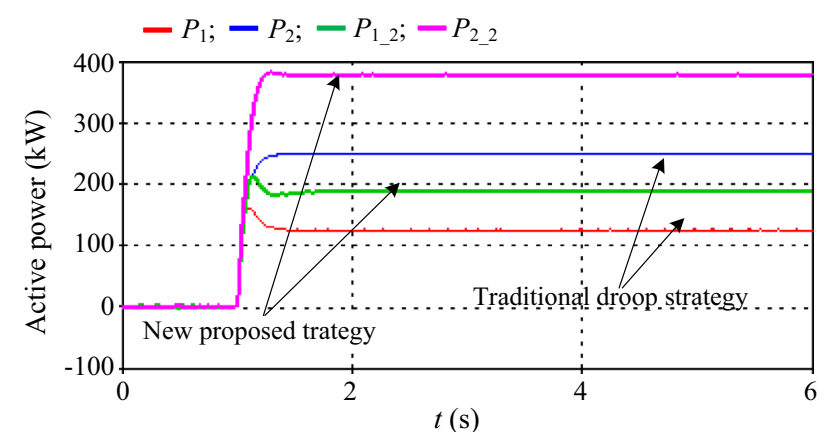

(a) Active power sharing

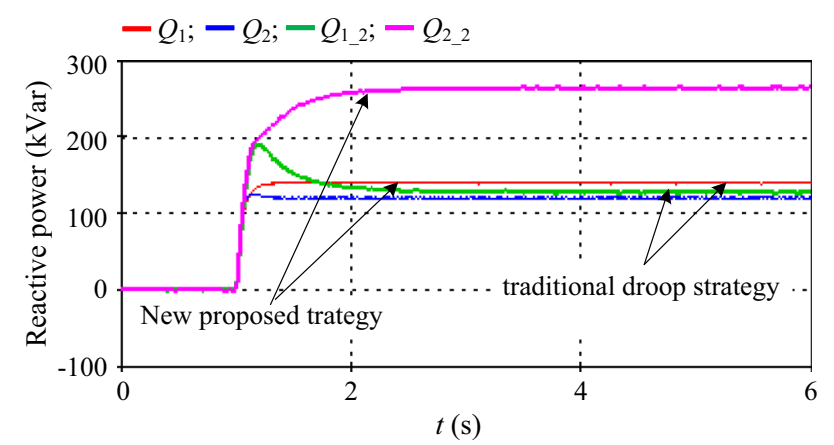

(b) Reactive power sharing

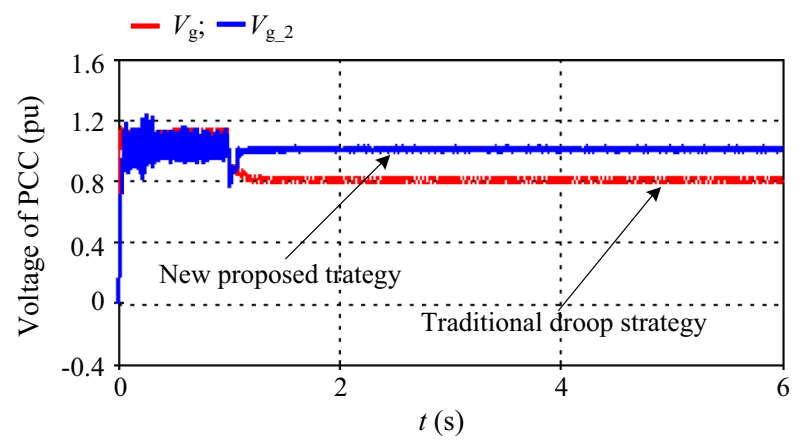

(c) AC common bus voltage

\begin{tabular}{|c|c|c|c|c|c|c|c|c|c|c|c|}
\hline \multirow[t]{2}{*}{ DG } & \multirow{2}{*}{$\begin{array}{l}\text { Rated } \\
\text { capacity } \\
\text { (MVA) }\end{array}$} & \multirow{2}{*}{$\begin{array}{l}\text { Rated } \\
\text { voltage } \\
\text { amplitude } \\
(\mathrm{kV})\end{array}$} & \multirow{2}{*}{$\begin{array}{l}\text { Rated } \\
\text { frequency } \\
(\mathrm{Hz})\end{array}$} & \multicolumn{2}{|c|}{ LC filter } & \multicolumn{3}{|c|}{ Transformer } & \multirow{2}{*}{$\begin{array}{l}\text { Frequency } \\
\text { droop } \\
\text { coefficients }\end{array}$} & \multirow{2}{*}{$\begin{array}{l}\text { Voltage } \\
\text { droop } \\
\text { coefficients }\end{array}$} & \multirow{2}{*}{$\begin{array}{l}\mathrm{AC} \\
\text { common } \\
\text { bus load } \\
Z_{\text {load }}(\Omega)\end{array}$} \\
\hline & & & & $L(\mathrm{mH})$ & $C(\mu \mathrm{F})$ & $\begin{array}{l}\text { Capacity } \\
\text { (MVA) }\end{array}$ & $\begin{array}{l}\text { Output } \\
\text { impedance } \\
(\Omega)\end{array}$ & $\begin{array}{l}\text { Voltage } \\
\text { ratio }\end{array}$ & & & \\
\hline 1 & $0.2+\mathrm{j} 0.15$ & 8.156 & 50 & 0.47 & 120 & 0.5 & 20 & $\begin{array}{l}380 \mathrm{~V} / \\
10 \mathrm{kV}\end{array}$ & $2.5 \times 10^{-6}$ & $1.36 \times 10^{-3}$ & $116+j 80$ \\
\hline 2 & $0.4+\mathrm{j} 0.3$ & 8.156 & 50 & 0.47 & 120 & 1.0 & 10 & $\begin{array}{c}380 \mathrm{~V} / \\
10 \mathrm{kV}\end{array}$ & $1.25 \times 10^{-6}$ & $6.8 \times 10^{-4}$ & \\
\hline
\end{tabular}

Fig. 5 Comparison between new robust droop control and conventional droop control

Table 1 Simulation parameters 
$K_{\mathrm{e}} \sum_{i=1}^{n} \frac{V_{\mathrm{T}}-V_{\mathrm{T} i}}{m_{i}}=\sum_{i=1}^{n} \Delta Q_{i}$

According to (21), the voltage $V_{\mathrm{T}}$ can be described as

$V_{\mathrm{T}}=m \sum_{i=1}^{n} \frac{V_{\mathrm{T} i}}{m_{i}}$

where $m=1 / \sum_{i=1}^{n} \frac{1}{m_{i}}$.

Based on the above analysis, the error degree of reactive power sharing $\rho_{i}$ can be expressed as

$\rho_{i}=\frac{\Delta Q_{i}}{Q_{\text {desired }}}=\frac{K_{\mathrm{e}}}{m_{i} Q_{\text {desired }}}\left(V_{\mathrm{T}}-V_{\mathrm{T} i}\right)$

Substitute (16) and (22) to (23), it can be obtained that

$\rho_{i}=\frac{K_{\mathrm{e}} S}{m_{i} S_{i} Q_{\text {load }}}\left(m \sum_{j=1}^{n} \frac{V_{\mathrm{T} j}}{m_{j}}-V_{\mathrm{T} i}\right)$

where $S=\sum^{n} S_{i}$. It is seen that $\rho_{i}$ mainly depends on $V_{\mathrm{T} i}$, $Q_{\text {load }}$ and $K_{\mathrm{e}}^{i=1}$ in a special high-voltage microgrid with the proposed local robust droop controller scheme. However, the parameters in (24) may be interactional, such as $V_{\mathrm{T} i}$ with $Q_{\text {load }}$. Accordingly, the following Section will analyze influences of $K_{\mathrm{e}}, Q_{\text {load }}$ and $X_{\mathrm{L} i}$ on $\rho_{i}$ in detail.

\section{Relationship between load sharing and system parameters}

In order to accurately show the influence of line impedance and robust coefficient $K_{\mathrm{e}}$ on the load sharing accuracy, the accurate relationship model between the load sharing and system parameters is presented in this section. It is known that $\boldsymbol{V}_{\mathbf{T} i}$ and $\boldsymbol{V}$ satisfy

$\mathbf{V}=V_{\mathrm{T} i} \angle \delta_{\mathrm{T} i}-\Delta \mathbf{V}_{\mathrm{L} i}$

where $\delta_{\mathrm{T} i}$ is phase angle of $V_{\mathrm{T} i} ; \Delta \boldsymbol{V}_{\mathrm{L} i}$ is voltage drop due to the line impedance.

Since the phase angle difference $\delta_{\mathrm{T} i}$ between $\boldsymbol{V}_{\mathrm{T} i}$ and $\boldsymbol{V}$ is small and negligible, so (26) can be derived.

$V_{T i}=V+\Delta V_{L i}$

Substitute (26) into (24), it can be obtained

$\rho_{i}=\frac{K_{\mathrm{e}} S}{m_{i} S_{i} Q_{\mathrm{load}}}\left(m \sum_{j=1}^{n} \frac{\Delta V_{\mathrm{L} j}}{m_{j}}-\Delta V_{\mathrm{L} i}\right)$

Based on the power flow calculation, voltage drop $\Delta V_{\mathrm{L} i}$ can be calculated as

$\Delta V_{\mathrm{L} i}=\frac{P_{i} R_{\mathrm{L} i}+Q_{i} X_{\mathrm{L} i}}{V}$

where $R_{\mathrm{L} i}$ and $X_{\mathrm{L} i}$ are the resistive and inductive part of line impedance, respectively.

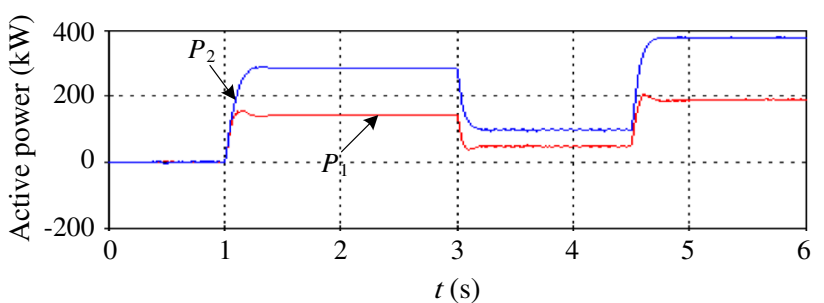

(a) Active power

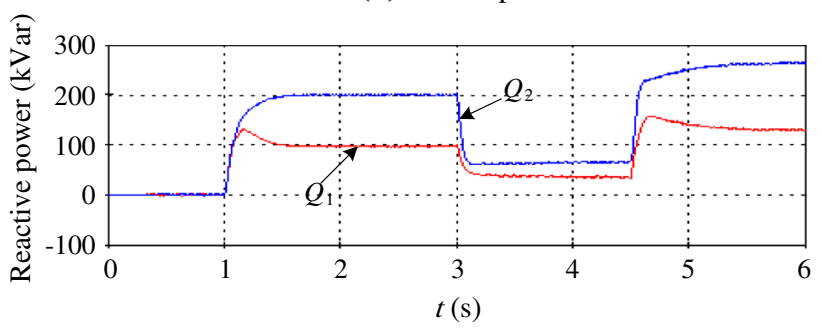

(b) Reactive power

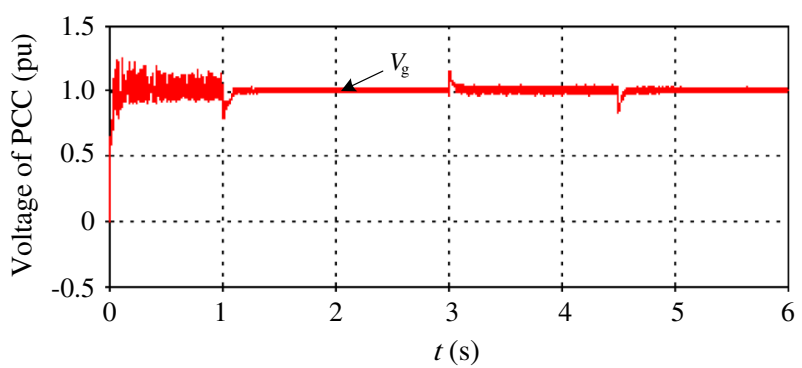

(c) AC common bus voltage

Fig. 6 Performance of new robust droop control with load variation

In the high-voltage microgrid, $X_{\mathrm{L} i}$ is the main part of line impedance, and $V$ is approximately equal to $E^{*}$, so (28) can be converted to

$\Delta V_{\mathrm{L} i}=\frac{Q_{i} X_{\mathrm{L} i}}{E^{*}}$

Substitute (29) into (27), (30) is derived.

$\rho_{i}=\frac{K_{\mathrm{e}} S}{m_{i} S_{i} E^{*} Q_{\text {load }}}\left(m \sum_{j=1}^{n} \frac{Q_{j} X_{\mathrm{L} j}}{m_{j}}-Q_{i} X_{\mathrm{L} i}\right)$

Based on (15), (26) and (29), (31) can be obtained.

$V=E^{*}-\frac{m_{i}}{K_{\mathrm{e}}} Q_{i}-\Delta V_{\mathrm{L} i}=E^{*}-m_{\mathrm{eq} i} Q_{i}$

where $m_{\mathrm{eq} i}=\frac{m_{i}}{K_{\mathrm{e}}}+\frac{X_{\mathrm{L} i}}{E^{*}}$.

Assume that

$V=E^{*}-m_{\mathrm{eq}} Q_{\text {load }}$

where $m_{\text {eq }}$ is the equivalent droop coefficient of $V$ versus reactive power $Q_{\text {load. }}$.

Based on (20), (31) and (32), (33) can be obtained.

$Q_{i}=\frac{m_{\mathrm{eq}}}{m_{\mathrm{eq} i}} Q_{\text {load }}$ 
where $m_{\mathrm{eq}}=1 / \sum_{i=1}^{n} \frac{1}{m_{\mathrm{eq}}}$.

Substitute (33) into (30), then

$\rho_{i}=\frac{K_{\mathrm{e}} S}{m_{i} S_{i} E^{*}}\left(m \sum_{j=1}^{n} \frac{1}{m_{j}} \frac{m_{\mathrm{eq}} X_{\mathrm{L} j}}{m_{\mathrm{eq} j}}-\frac{m_{\mathrm{eq}} X_{\mathrm{L} i}}{m_{\mathrm{eq} i}}\right)$

Naturally, (34) can be utilized as the mathematic model to analyze the power sharing performance of the proposed control strategy. Noted that $\rho_{i}$ only depends on the line impedance $X_{\mathrm{L} i}$ and $K_{\mathrm{e}}$, and it has no difference with reactive power output $Q_{\text {load }}$ or active power output $P_{\text {load }}$ when parameters $m_{i}, S_{i}, S$ and $E^{*}$ are constant.

Assume that the sum of inverter $n=2$ in the highvoltage microgrid system, and then the ratio coefficient of capacity of $\mathrm{DG}_{2}$ to that of $\mathrm{DG}_{1}$ is $k$. At the same time, the parameter $m_{1}$ is set to $k$ times as much as $m_{2}$. Accordingly, $S_{i} / S$ is equal to $k^{i-1} /(1+k)$, and (34) can be simplified as

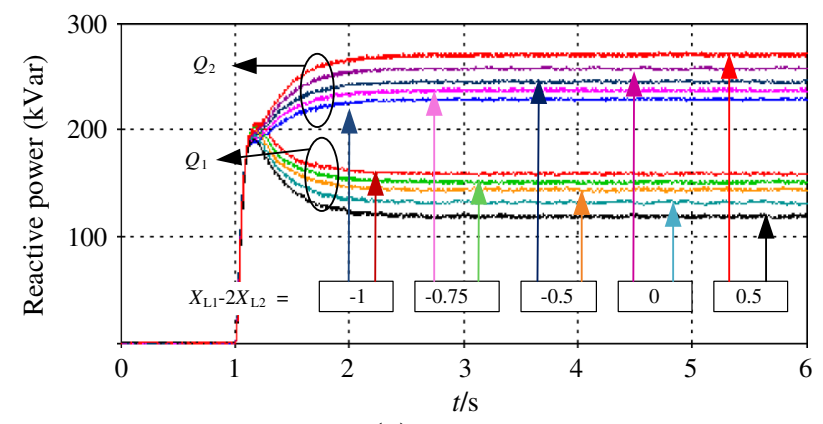

(a) $Z_{\mathrm{LB}}=0.5 \Omega$

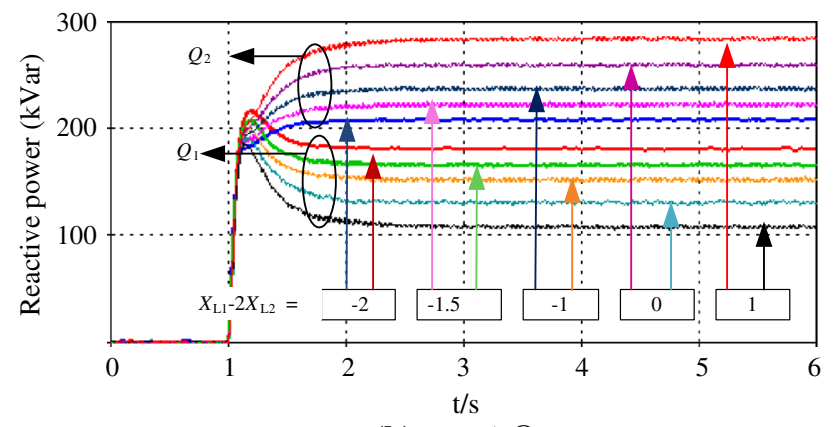

(b) $Z_{\mathrm{LB}}=1 \Omega$

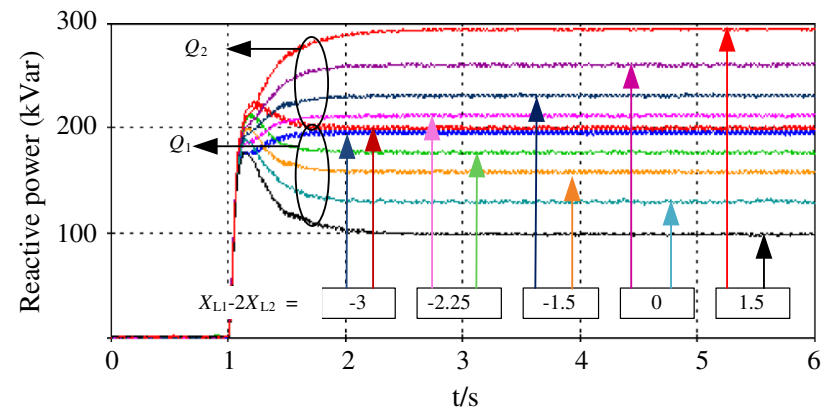

(c) $Z_{\mathrm{LB}}=1.5 \Omega$

Fig. 7 Reactive power sharing of DGs with different line impedance $\rho_{i} \approx(-1)^{i} \frac{k^{3-2 i} K_{\mathrm{e}}\left(X_{\mathrm{L} 1}-k X_{\mathrm{L} 2}\right)}{(1+k) m_{i} E^{*}} \quad i=1,2$

Equation (35) shows that the larger difference between $k X_{\mathrm{L} 2}$ and $X_{\mathrm{L} 1}$ is, the larger $\left|\rho_{i}\right|$ will be, and $\left|\rho_{i}\right|$ will be zero when $X_{\mathrm{L} 1}=k X_{\mathrm{L} 2}$. In addition, it should also be noted that the value of $\rho_{x}$ may be positive or negative, e.g., $\rho_{1}>0$ and $\rho_{2}<0$ when $X_{\mathrm{L} 1}>k X_{\mathrm{L} 2}, \rho_{2}>0$ and $\rho_{1}<0$ when $X_{\mathrm{L} 1}>k X_{\mathrm{L} 2} . \rho_{i}>0$ represents that the reactive power output of inverter $i$ exceeds the desired power output, i.e., $Q_{i}>Q_{\text {desired}}$, and the DG is on the risk of overload. Whereas, it indicates that the reactive power output of $\mathrm{DG}_{i}$ is less than the desired output, e.g., $Q_{i}<Q_{\text {desired }}$, and the $\mathrm{DG}_{i}$ is on the condition of under-load.

Taking the absolute value of the both sides of (35) and (36) can be obtained.

$\left|\rho_{i}\right| \approx \frac{k^{3-2 i} K_{\mathrm{e}}\left|X_{\mathrm{L} 1}-k X_{\mathrm{L} 2}\right|}{(1+k) m_{i} E^{*}}$

According to (35), $K_{\mathrm{e}}$ can be represented as

$K_{\mathrm{e}} \approx \frac{(1+k) m_{i} E^{*}\left|\rho_{i}\right|}{k^{3-2 i}\left|X_{\mathrm{L} 1}-k X_{\mathrm{L} 2}\right|}$

Thus, to ensure $\left|\rho_{i}\right| \leq 0.1, K_{\mathrm{e}}$ has to satisfy

$K_{\mathrm{e}} \leq \frac{(1+k) m_{i} E^{*}}{10 k^{3-2 i}\left|X_{\mathrm{L} 1}-k X_{\mathrm{L} 2}\right|}$

In addition, it is necessary to consider the voltage robustness at the moment of designing $K_{\mathrm{e}}$. As shown in (15), the robustness of voltage can be guaranteed only if $K_{\mathrm{e}}$ is larger than 1 . If $K_{\mathrm{e}}$ is less than 1, the equivalent voltage droop coefficient $m_{i} / K_{\mathrm{e}}$ will be larger than the setting droop coefficient $m_{i}$ which indicates that the voltage will drop more not less than the reactive power drops. For example, if $i=1, k=2, E^{*}=8.156 \mathrm{kV}, m_{1}=3 \times 10^{-3}$ and $X_{\mathrm{L} 1}-2 X_{\mathrm{L} 2}=1$, then $1<K_{\mathrm{e}} \leq 3.67$. Thus, to enhance the robustness of voltage and improve the accurateness of sharing load at the same time, comprehensive consideration should be taken to select the most suitable $K_{\mathrm{e}}$.

So the following section will validate the incidence of impedance $X_{\mathrm{L} i}$ and robust coefficient $K_{\mathrm{e}}$ on the error degree of reactive power sharing $\rho_{i}$ by simulation and its results.

\section{Simulation validation}

In order to show the reactive power sharing accuracy with the proposed robust droop control, simulations are carried out within PSCAD/EMTDC, and the topology of the studied high-voltage microgrid is shown in Fig. 2 with $i=2$. The simulation parameters are summarized in Table 1. In addition, the simulation starts at $t=0 \mathrm{~s}$. At $t=1 \mathrm{~s}, \mathrm{DG}_{1}$ and $\mathrm{DG}_{2}$ are put into operation to supply $Z_{\text {load }}$ 
Table 2 Systems parameters and reactive power supplied by DG with different line impedance

\begin{tabular}{lllll}
\hline$Z_{\mathrm{LB}}(\Omega)$ & $\mathrm{Z}_{\mathrm{L} 1} / \mathrm{Z}_{\mathrm{L} 2}(\Omega)$ & $X_{\mathrm{L} 1}-2 X_{\mathrm{L} 2}(\Omega)$ & $Q_{1} / Q_{2}(\mathrm{kVar})$ & $\rho_{1} / \rho_{2}$ \\
\hline 0.5 & $0 / 0.5$ & -1 & $155 / 235$ & $0.192 /-0.096$ \\
& $0.25 / 0.5$ & -0.75 & $150 / 240$ & $0.154 /-0.077$ \\
& $0.5 / 0.5$ & -0.5 & $145 / 245$ & $0.115 /-0.058$ \\
& $0.5 / 0.25$ & 0 & $130 / 260$ & $-0 / 0$ \\
& $0.5 / 0$ & 0.5 & $115 / 275$ & $0.115 / 0.058$ \\
1.0 & $0 / 1$ & -2 & $180 / 210$ & $0.385 / 0.192$ \\
& $0.5 / 1$ & -1.5 & $160 / 230$ & $0.231 /-0.115$ \\
& $1 / 1$ & -1 & $155 / 235$ & $0.192 /-0.096$ \\
& $1 / 0.5$ & 0 & $130 / 260$ & $0 / 0$ \\
1.5 & $1 / 0$ & 1 & $105 / 285$ & $-0.192 / 0.096$ \\
& $0 / 1.5$ & -3 & $200 / 190$ & $0.538 /-0.269$ \\
& $0.75 / 1.5$ & -2.25 & $185 / 205$ & $0.423 /-0.211$ \\
& $1.5 / 1.5$ & -1.5 & $160 / 230$ & $0.231 /-0.115$ \\
& $1.5 / 0.75$ & 0 & $130 / 260$ & $0 / 0$ \\
& $1.5 / 0$ & 1.5 & $100 / 290$ & $-0.231 / 0.115$ \\
\hline
\end{tabular}

connected the AC common bus simultaneously. Simulation process finishes at $t=6 \mathrm{~s}$.

\subsection{Comparison between proposed robust droop control and conventional droop control}

The simulations are carried out with the conventional voltage droop coefficients divided by $K_{\mathrm{e}}=5$ so that the equivalent voltage droop coefficient is the same as the one in the proposed controller. Expecting that the voltage droop could be comparable with the one achieved with the proposed robust droop scheme. The line impedances $Z_{\mathrm{L} 1}=\mathrm{j} 0.9425 \Omega, Z_{\mathrm{L} 2}=\mathrm{j} 0.314 \Omega$.

Figure 5 shows the simulation results of both the proposed new robust droop control and the conventional droop control. $P_{i \_2}$ and $Q_{i \_2}$ are the active and reactive power of $\mathrm{DG}_{i}$ and $V_{\mathrm{g} \_2}$ is the AC common bus voltage when the new robust droop control is applied. $P_{i}$ and $Q_{i}$ are the active power and reactive power of $\mathrm{DG}_{i}$ and $V_{\mathrm{g}}$ is the $\mathrm{AC}$ common bus voltage when the conventional droop control is applied.

In Fig. 5a, when the simulation is in steady state at about $t=2 \mathrm{~s}$, the active power output of DGs with different droop controls are that $P_{2 \_2}=2 P_{1 \_2}=3.9 \times 10^{2}$ $\mathrm{kW}$ and $P_{2}=2 P_{1}=2.5 \times 10^{2} \mathrm{~kW}$, which indicates that the active power sharing among DGs could be achieved either through the proposed droop control or the conventional droop control. However, the proposed robust droop control can supply higher power.

In Fig. $5 \mathrm{~b}$, it can be seen that $Q_{1}=1.9 \times 10^{2} \mathrm{kVar}$, $Q_{2}=2.5 \times 10^{2} \mathrm{kVar}$, the reactive power sharing is unable to be achieved with the conventional droop control due to the mismatched line impedances. However, in the proposed robust droop control system, $Q_{2 \_2}=1.22 \times 10^{5} \mathrm{kVar}$ is nearly equal to $2 Q_{12}=2.66 \times 10^{5} \mathrm{kVar}$, which means that reactive power sharing has be improved much when the proposed control scheme is adopted.

As shown in Fig. 5c, the AC common bus voltage with the proposed droop control can be maintained around the rated voltage, but the voltage with traditional droop control is only about $3 / 4$ of the rated voltage, which agrees with the analysis of (5) in Section 3. In a word, the tradeoff between the load sharing accuracy and voltage regulation can be restrained successfully as that in [8], but it is easier to be implemented with the proposed droop control.

\subsection{Performance of proposed robust droop control with load variations}

In the section, the influence of load changes on load sharing is analyzed. The line impedances are assumed as $Z_{\mathrm{L} 1}=0.9425 \Omega$ and $Z_{\mathrm{L} 2}=0.314 \Omega$, and the robust coefficient $K_{\mathrm{e}}$ is set to 5 . The simulation results are shown in Fig. 6.

At $t=1 \mathrm{~s}$, the load with $3 / 4$ rated power is connected to the microgrid. At $t=3 \mathrm{~s}$, the load decreases to $1 / 4$ rated power. At $t=4.5 \mathrm{~s}$, the load increases to the rated power. From Fig. 6a, b, it can be seen that the ratio of active or reactive power output of $D_{1}$ to that of $D_{2}$ is about $1 / 2$ whatever the active power or reactive power load changes. It can be seen from Fig. 6c, the AC common bus voltage is always maintained at the rated value. Thus, it can be concluded that the variation of active or reactive load has little influence on the load sharing performance with the proposed droop control. 


\subsection{Influence of line impedance on load sharing accuracy}

According to the analysis in Section 4, the influence of line impedance on the degree error of reactive power sharing $\rho_{x}$ is shown in (33). And it also illustrates that $\rho_{x}$ mainly depends on $X_{\mathrm{L} 1}-k X_{\mathrm{L} 2}$ with a constant $K_{\mathrm{e}}$. So we can explore how line impedance impacts load sharing accuracy based on (34). Figure 7 shows the load sharing performance of the proposed robust droop control with different line impedances.

Assume that the basic value $Z_{\mathrm{LB}}$ is equal to the maximum value of line impedances, i.e., $Z_{\mathrm{LB}}=Z_{\mathrm{Lmax}}$. Thus, $Z_{\mathrm{LB}}$ is the level of line impedance, which restrains the range interval of $X_{\mathrm{L} 1}-k X_{\mathrm{L} 2} . Z_{\mathrm{LB}}$ is set to $0.5,1$ and $1.5 \Omega$ in this paper. In addition, $K_{\mathrm{e}}$ is equal to 5 and other parameters are the same as in Section 5.1. The system parameters and reactive power supplied by each DG are shown in Table 2. $Q_{1}$ and $Q_{2}$ are the reactive power output of $\mathrm{DG}_{1}$ and $\mathrm{DG}_{2}$ at the high-voltage side of coupling transformer. In Fig. 7, $X_{\mathrm{L} 1}-2 X_{\mathrm{L} 2}$ is the parameter of line impedance. According to Fig. 7 and Table 2, it can be observed that

1) $\rho_{1}>0$ and $\rho_{2}<0$ when $X_{\mathrm{L} 1}-2 X_{\mathrm{L} 2}<0$, and the reactive power output of $\mathrm{DG}_{1}$ is larger than its desired power and the reactive power output of $\mathrm{DG}_{2}$ is less than its desired power. On the contrary, $\rho_{1}<0$ and $\rho_{2}>0$ when $X_{\mathrm{L} 1}-2 X_{\mathrm{L} 2}>0$, and the reactive power output of $\mathrm{DG}_{1}$ is less than its desired power and the reactive power output of $\mathrm{DG}_{2}$ is larger than its desired power.

2) The smaller the absolute value of $X_{\mathrm{L} 1}-2 X_{\mathrm{L} 2}$ is, the more accurate the load sharing among DGs will be. In another word, the closer to zero $X_{\mathrm{L} 1}-2 X_{\mathrm{L} 2}$ is, the smaller $\rho_{1}$

and $\rho_{2}$ are, and the better of the load sharing performance among DGs would be as result.

\subsection{Influence of robust coefficient $K_{\mathrm{e}}$ on load sharing accuracy}

Based the simulations in Section 5.1, assume that the line impedance $Z_{\mathrm{L} 1}=0.9425 \Omega, Z_{\mathrm{L} 2}=-0.314$ and $X_{\mathrm{L} 1}-2 X_{\mathrm{L} 2}>0$, the simulation results are shown in Fig. 8 with the robust coefficient $K_{\mathrm{e}}$ equaling to $10,5,1$ and 0.2 , respectively.

In Fig. 8a, b, $P_{i}$ and $Q_{i}$ are the reactive and active power output of $\mathrm{DG}_{i}$ with different $K_{\mathrm{e}}$. Figure $8 \mathrm{c}$ shows the AC common bus voltage $V$ with different $K_{\mathrm{e}}$.

The following can be observed from Fig. 8 and Table 3 .

1) The change of $K_{\mathrm{e}}$ has no effects on the active power sharing. The active power sharing can be always achieved among DGs when $P_{2}=2 P_{1}$.

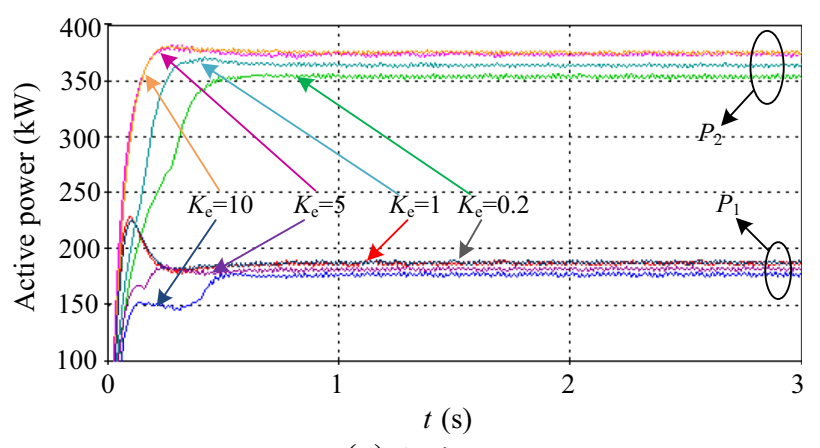

(a) Active power

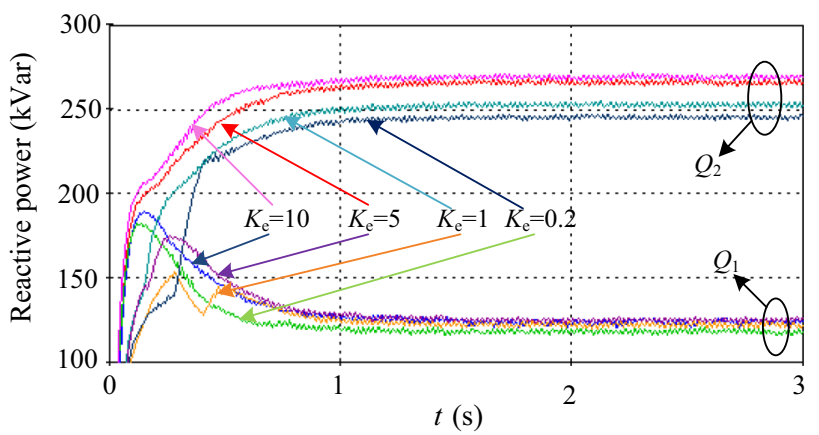

(b) Reactive power

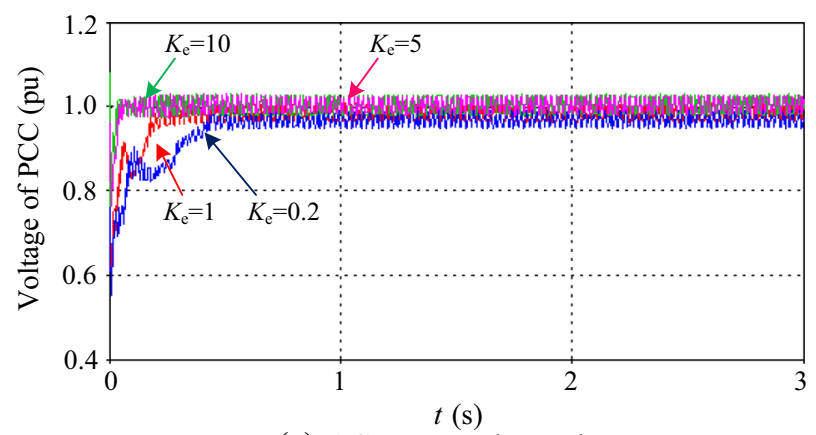

(c) $\mathrm{AC}$ common bus voltage

Fig. 8 Power sharing and AC common bus voltage

Table 3 Voltage, reactive power and $\rho_{i}$ with different $K_{\mathrm{e}}$

\begin{tabular}{llllll}
\hline$K_{\mathrm{e}}$ & $V$ & $Q_{2}(\mathrm{kVar})$ & $Q_{1}(\mathrm{kVar})$ & $\rho_{2}$ & $\rho_{1}$ \\
\hline 10 & 0.99 & 269 & 118 & 0.1080 & -0.2160 \\
5 & 0.99 & 266 & 122 & 0.0290 & -0.0570 \\
1 & 0.98 & 253 & 124 & 0.0660 & -0.0132 \\
0.2 & 0.97 & 247 & 123 & 0.0014 & -0.0027 \\
\hline
\end{tabular}

2) The absolute value of $\rho_{i}$, i.e., degree error of the reactive power sharing of $\mathrm{DG}_{i}$, increases gradually along with the increase of $K_{\mathrm{e}}$.

3) In addition, $Q_{2}$ increases gradually along with the increase of $K_{\mathrm{e}}$, but $Q_{1}$ decreases except that when $K_{\mathrm{e}}=0.2$. At this time, the reactive power output of 
$\mathrm{DG}_{1}$ is second largest in Fig. $8 \mathrm{~b}$ and Table 3 because the rate of drop of voltage is larger than rate of increment of $K_{\mathrm{e}}$. What is more, the reactive power output of $\mathrm{DG}_{2}$ is always larger than the desired power, and reactive power output of $\mathrm{DG}_{1}$ is less than the desired power. $\rho_{1}>0$ and $\rho_{2}<0$ when $X_{\mathrm{L} 1}-2 X_{\mathrm{L} 2}>0$, which are consistent with (33) and the simulation results in Section 5.1.

4) However, the AC common bus voltage drops slightly with the decrease of $K_{\mathrm{e}}$. Meanwhile, it is a pity that the total output powers of the two DGs decreases slightly due to the drop of ac common bus voltage. So choosing the suitable $K_{\mathrm{e}}$ is necessary to ensure voltage robustness and power sharing.

\section{Conclusions}

In this paper, a new robust droop control method for high-voltage microgrid is proposed. Based on the theoretical analysis and simulation studies in PSCAD/EMTDC, the following conclusions are drawn.

1) As the dominated part of grid impedance, the impact of transformer impedance on the reactive power sharing accuracy is mitigated significantly. Because the local signals at the high voltage side of transformer are detected as the feedback signals within the proposed robust droop control method, so the proposed method is easy and effectively to apply in such highvoltage microgrid.

2) The drawback caused by the line impedance difference can be eliminated with the optimal selection of robust coefficient $K_{\mathrm{e}}$ to a large extent. Besides, the ac common bus voltage can be maintained in a certain range with the proposed robust droop control.

3) The proposed robust droop control can not only be used in multi-microsource and high-voltage microgrid with centralized loads but also with distributed loads. Besides, the proposed robust droop control is easy to be implemented.

Acknowledgment This project was partially supported by the National Natural Science Foundation of China (No. 51207048), the National High Technology Research and Development of China (No. 2014AA052601) and Higher National Excellent Doctoral Dissertation of Special Funds (No. 201441).

Open Access This article is distributed under the terms of the Creative Commons Attribution 4.0 International License (http:// creativecommons.org/licenses/by/4.0/), which permits unrestricted use, distribution, and reproduction in any medium, provided you give appropriate credit to the original author(s) and the source, provide a link to the Creative Commons license, and indicate if changes were made.

\section{References}

[1] Lasseter RH, Piagi P (2004) Microgrid: a conceptual solution. In: Proceedings of the IEEE 35th annual power electronics specialists conference (PESC'04), vol 6, Aachen, 20-25 June 2004, pp 4285-4290

[2] Blaabjerg F, Guerrero JM (2011) Smart grid and renewable energy systems. In: Proceedings of the 2011 international conference on electrical machines and systems (ICEMS'11). Beijing, 20-23 Aug 2011, 10 pp

[3] Wang CS, Wang SX (2008) Study on some key problems related on distributed generation systems. Automat Electr Power Syst 32(20):1-4 (in Chinese)

[4] Chandorkar MC, Divan DM, Adapa R (1993) Control of parallel connected inverters in standalone AC supply systems. IEEE Trans Ind Appl 29(1):136-143

[5] Wu D, Tang F, Vasquez JC, et al (2014) Control and analysis of droop and reverse droop controllers for distributed generations. In: Proceedings of the 11th international multi-conference on systems, signals \& devices (SSD'14), Barcelona, 11-14 Feb 2014, 5 pp

[6] Vandoorn TL, Meersman B, de Kooning JDM et al (2012) Directly-coupled synchronous generators with converter behavior in islanded microgrids. IEEE Trans Power Syst 27(3):1395-1406

[7] Guerrero JM, Vasquez JC, Matas J et al (2009) Control strategy for flexible microgrid based on parallel line-interactive UPS systems. IEEE Trans Ind Electron 56(3):726-736

[8] Zhong QC (2013) Robust droop controller for accurate proportional load sharing among inverters operated in parallel. IEEE Trans Ind Electron 60(4):1281-1290

[9] de Brabandere K, Bolsens B, van den Keybus J et al (2007) A voltage and frequency droop control method for parallel inverters. IEEE Trans Power Electron 22(4):1107-1115

[10] Guerrero JM, de Vicuña LG, Matas J et al (2005) Output impedance design of parallel-connected UPS inverters with wireless load-sharing control. IEEE Trans Ind Electron 52(4):1126-1135

[11] Rokrok E, Golshan MEH (2010) Adaptive voltage droop scheme for voltage source converters in an islanded multibus microgrid. IET Gener Transm Distrib 4(5):562-578

[12] Li YW, Kao CN (2009) An accurate power control strategy for power-electronics-interfaced distributed generation units operating in a low-voltage multibus microgrid. IEEE Trans Power Electron 24(12):2977-2988

[13] He JW, Li YW (2011) Analysis, design, and implementation of virtual impedance for power electronics interfaced distributed generation. IEEE Trans Ind Appl 47(6):2525-2538

[14] Sao CK, Lehn PW (2005) Autonomous load sharing of voltage source converters. IEEE Trans Power Deliver 20(2):1009-1016

[15] Mao MQ, Shen K, Chang LC (2013) Accurate output power control of inverters for microgrids based on local measurement. In: Proceedings of the 4th IEEE international symposium on power electronics for distributed generation systems (PEDG'13), Rogers, 8-11 Jul 2013, 7 pp

[16] Gu HR, Guo XQ, Wang D, et al (2012) Real-time grid impedance estimation technique for grid- connected power converters. In: Proceedings of the 2012 IEEE international symposium on industrial electronics (ISIE'12), Hangzhou, 28-31 May 2012, pp 1621-1626

[17] Chen CL, Wang YB, Lai JS et al (2010) Design of parallel inverters for smooth mode transfer microgrid applications. IEEE Trans Power Electron 25(1):6-15

[18] Shahidehpour M, Khodayar M, Barati M (2012) Campus microgrid: High reliability for active distribution systems. In: 
Proceedings of the IEEE Power \& Energy Society general meeting, San Diego, 22-26 July 2012, 2 pp

[19] Yang H, Zhao RX, Xin HH et al (2013) Development and research status of island power systems. Trans China Electrotech Soc 28(11):95-102 (in Chinese)

[20] Lee CT, Chu CC, Cheng PT (2010) A new droop control method for the autonomous operation of distributed energy resource interface converters. In: Proceedings of the 2010 IEEE energy conversion congress and exposition (ECCE'10), Atlanta, 12-16 Sept 2010, pp 702-709

[21] He YZ, Wen ZY (2002) Electric power system analysis. In: Huazhong University of Sicience and Technology Press, Wuhan, $27 \mathrm{pp}$ (in Chinese)

Zhikang SHUAI received the B.S. and Ph.D. degree from the College of Electrical and Information Engineering, Hunan University, China, in 2005 and 2011, respectively, all in electrical engineering. He joined Hunan University as an Assistant Professor from 2009 to 2012, an Associate Professor in 2013, and has been a Professor since 2014. His current research interests include power quality control, power electronics, and microgrid stability. Dr. SHUAI is a recipient of the 2010 National Scientific and Technological Awards of China, the 2012 Hunan Technological Invention Awards of China, the 2007 Scientific and Technological Awards from the National Mechanical Industry Association of China.

Shanglin MO received the B.S. from the College of Electric Engineering and Automation, Chongqing University of Posts and Telecommunications, Chongqing, China, in 2013. He is currently pursuing the M.S. degree in Electric Engineering at the College of Electrical and Information Engineering, Hunan University, China. His research interests include power electronics and microgrid stability.

Jun WANG received the B.S. degree at Huazhong University of Science and Technology, Wuhan, China in 2000. He received the M.S. degree in Institute of Semiconductors, Chinese Academy of Sciences, Beijing, China in 2003. He received the M.E. degree at University of South Carolina, Columbia, SC, USA in 2005, and the $\mathrm{Ph} . D$. degree at North Carolina State University, Raleigh, NC, USA in 2010 respectively, all in Electrical Engineering. He then worked as a device design engineer at Texas Instruments, Inc. in Bethlehem, PA, USA between 2010 and 2013. He became a professor in the College of Electrical and Information Engineering at Hunan University in 2014. He has authored and coauthored more than 30 journal and conference publications and holds 2 issued U.S. patents. His research interests include power semiconductor devices and their applications in power electronics systems.

Z. John SHEN received B.S. from Tsinghua University, China, in 1987, and M.S. and Ph.D. degrees from Rensselaer Polytechnic Institute, Troy, NY, in 1991 and 1994, respectively, all in electrical engineering. Between 1994 and 1999, he held a variety of positions including Senior Principal Staff Scientist with Motorola. He was on faculty of the University of Michigan-Dearborn between 1999 and 2004, and the University of Central Florida between 2004 and 2012. He joined the Illinois Institute of Technology in 2013 as the Grainger Chair Professor in Electrical and Power Engineering. He has also held a courtesy professorship with Hunan University, China since 2007; and with Zhejiang University, China since 2013. His research interests include power electronics, power semiconductor devices and ICs, automotive electronics, renewable and alternative energy systems, and electronics manufacturing. He has published over 150 journal and conference articles, and holds 13 issued and several pending U.S. patents in these areas. He is a recipient of the 2012 IEEE Region 3 Outstanding Engineer Award, the 2003 NSF CAREER Award, the 2006 IEEE Transaction Paper Award from IEEE Society of Power Electronics, the 2003 IEEE Best Automotive Electronics Paper Award from IEEE Society of Vehicular Technology, and the 1996 Motorola Science and Technology Award. He has been an active volunteer in the IEEE Power Electronics Society (PELS), and has served as VP of Products 2009-2012, Associate Editor and Guest Editor in Chief of the IEEE Transactions on Power Electronics, technical program chair and general chair of several major IEEE conferences.

Wei TIAN received the B.S. degree in mathematics from Shandong University, China, in 2001, the M.S. degree in system engineering from Xi' an Jiaotong University, China, in 2004, and the Ph.D. degree in electrical engineering from the Illinois Institute of Technology, Chicago, IL, USA, in 2011. He is a Visiting Scientist at the Robert W. Galvin Center for Electricity Initiative at the Illinois Institute of Technology. His research interests include power system restructuring, long-range planning, renewable energy integration and microgrid.

Yan FENG received the B.S. degree from the College of Electrical and Information Engineering, Hunan University, Changsha, China, in 2014. She is currently pursuing the M.S. degree in Electrical Engineering at the College of Electrical and Information Engineering, Hunan University, Changsha, China. Her research interests include power electronics and microgrid stability. 